\title{
Extensions of UML to Model Aspect-oriented Software Systems
}

\author{
Milena Guessi, Lucas Bueno Ruas Oliveira, and Elisa Yumi Nakagawa \\ Dept. of Computer Systems \\ University of São Paulo - USP \\ PO Box 668, 13560-970, São Carlos, SP, Brazil \\ \{milena, buenolro,elisa\}@icmc.usp.br
}

\begin{abstract}
Aspect-Oriented Programming (AOP) has arisen as a new technology to support a better SoC (Separation of Concerns), intending to contribute to the development of reusable, maintainable, and evolvable software systems. Aspects have been also explored in the early life cycle phases, aiming at contributing to a more adequate development of aspect-oriented software systems. In this perspective, in order to better represent these systems, a diversity of extensions of the UML (Unified Modeling Language) has been proposed; however, there is a lack of a complete panorama that identify all these extensions. This paper presents an overview about which are possibly all extensions of the UML to represent aspect-oriented software systems. For this, we have used a technique proposed by Evidence-Based Software Engineering (EBSE): the Systematic Mapping. As achieved results, we can observe a diversity of work; however, there is not a consensus about which are the more adequate or more used extensions. Based on this overview, interesting and important perspectives for future research can also be found.
\end{abstract}

Keywords: UML, Aspect-orientation, Systematic Mapping.

\section{INTRODUCTION}

Aspect-Oriented Programming (AOP) has arisen as an approach that supports a better SoC (Separation of Concerns) and more adequately reflects the way developers think about the system [14]. Essentially, AOP introduces a unit of modular implementation - the aspect - which has been typically used to encapsulate crosscutting concerns in software systems (i.e., concerns that are spread across or tangled with other concerns). Modularity, maintainability, and facility to write software can be achieved with AOP [17]. Aspects have also been explored in the early life cycle phases.

According to Baniassad et al. [2], aspects in early phases support easier identification and analysis of aspects during later activities and, as a consequence, a better SoC in the aspect-oriented software systems, i.e., systems that contain aspects. In order to adequately model these systems, it is observed a diversity of initiatives [5, 19]. In particular, UML (Unified Modelling Language) [20] has been investigated as a language to represent aspect-oriented software systems, since it is already widely used as in the academy as in the industry.

In another perspective, Evidence-Based Software Engineering (EBSE) [9] has recently arisen, inspired in the medicine area, and has given considerable contribution to the Software Engineering area. EBSE provides means by which the best current research evidence can be coupled with practical experience and human values into the decision making process regarding software development and maintenance [15]. Thus, EBSE can contribute to software engineering researchers and professionals to make decisions concerning the adoption of new technologies, including processes, techniques, methods, and so on. In this context, systematic mapping is a technique that provides a systematic way in order to comprehend a topic 
of research [4, 22]. Considering its relevance, systematic mapping for different domains can be found and, specifically for Software Engineering area, mapping for software testing [1] and for requirement specification [6] are two examples. In this perspective, the conduction of systematic mapping in order to identify all work that propose UML extensions to represent aspect-oriented systems seems also to be interesting.

The main objective of this paper is then to present a panorama containing possibly all research work that have investigated and/or extended UML to represent aspect-oriented software systems. For this, we have adopted and conducted a systematic mapping to investigate this topic of research. As main achieved results, we have observed that there are many research groups publishing different initiatives to the aspect-oriented modeling using UML. However, there is not a consensus about a unified solution for that modeling. It is worth highlighting that this work corresponds to a reconduction of the systematic mapping previously presented in [11], containing therefore updated results.

This paper is organized as follows. In Section 2 we present a brief overview on aspect-orientation, UML, and systematic mapping technique. In Section 3 we present the conducted systematic mapping. In Section 4 we discuss about achieved results. Finally, in Section 5 we summarize our contributions and discuss perspectives for further work.

\section{BACKGROUND AND RELATED WORK}

In the context of Aspect-Oriented Software Development (AOSD), identification of aspects during early phases of the software life cycle - for instance, requirement specification and architecture design - has been a recurrent issue in the literature. According to Baniassad [2], aspects in early phases support an easier identification and analysis of aspects during later activities, such as design and coding phases. In the last years, conferences, such as Aspect-Oriented Software Development (AOSD) Conference, Early Aspects workshops series and Workshop on Aspects in Architectural Description, have broadly discussed the use of aspects in these early phases. In order to deal with aspects in early phases related to modeling of aspect-oriented software systems, there is a diversity of initiatives [18, 21, 23]. In special, extensions to the UML can be also found [7, 12].

Currently, UML has been widely used in order to mainly facilitate development of object-oriented software systems. This standardized general-purpose modeling language includes a set of graphical notation techniques (also UML techniques or UML diagrams) to create visual models of software-intensive systems [20]. Its newest version (version 2.2) presents 14 techniques (such as Class Diagram, Sequence Diagram, and Component Diagram) divided into two categories (structural and behavioral) [20]. The diversity of UML techniques has therefore been basis for modeling of software systems with diverse characteristics, including aspect-oriented software systems.

In another perspective, it is noticed that when a research area is mature, there is almost always an increase in the number of reports and results made available. During the study of a new knowledge area, researchers usually conduct a bibliographical review (almost always an informal review) to identify publications related to a specific subject. For instance, Khan [13] conducted recently a survey on UML extensions to design aspect-oriented systems. Their study considered as relevant only eight works. The selection criteria used to select these studies was based mainly on previous background of the authors on the subject and was restricted to well-known events or those specific of aspect-orientation. The authors present an evaluation of each work considering, for instance, its coverage of the main constructs of aspect-oriented programming languages, which were these constructs, the UML technique used and if the work presents a case study. However, this kind of review do not use a systematic approach and do not offer any support to avoid bias during the selection of the publications that will be analyzed. Thus, it is important to have mechanisms to summarize and provide an overview about an area or topic of interest [22]. For this, EBSE has investigated and proposed the use of systematic mapping technique $[4,22]$. In this context, an individual evidence (for instance, a case study or an experimental study divulged in a publication/paper) which contributes to a systematic mapping is called primary study, while the result of a systematic mapping is a secondary study. Systematic mapping aims at providing an overview of a research area to assess the quantity and type of primary studies existing on a topic of interest [22]. In short, systematic mapping is conducted by planning, conduction of search and screening of primary studies using inclusion and exclusion criteria [4]. Besides that, systematic mapping also conducts data extraction and analysis through the identification of categories and classification of the primary studies in these categories. As a result, this technique provides maps (for instance, in table or graphical format) containing condensed information about a research area. 


\section{Systematic Mapping Application}

Our systematic mapping aims at identifying all primary studies that propose extension to the UML in order to represent aspect-oriented software systems. This systematic mapping considered studies published until February 5, 2011 and involved three people (a researcher in software engineering, a specialist in systematic mapping, and an undergraduate student). In order to conduct our systematic mapping, we have used the process presented in Figure 1. In short, it is composed by four steps: (i) systematic mapping planning; (ii) conduction of the search; (iii) selection of the primary studies; and (iv) analysis, classification, and map building. These steps are explained in more details during presentation of our systematic mapping. Following, we detail each step:

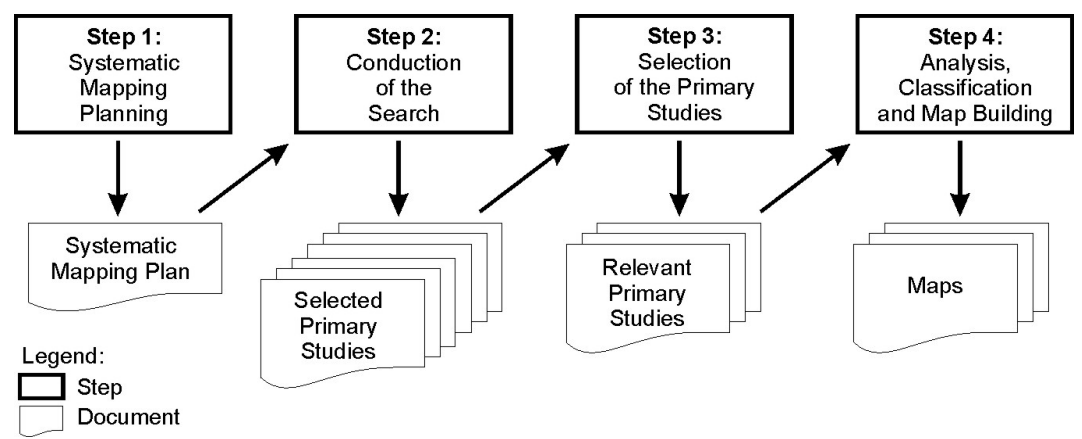

Figure 1: Systematic mapping process (Adapted from [22])

\subsection{Step 1: Systematic Mapping Planning}

In this step, it is established the systematic mapping plan that will be used as basis to conduct the systematic mapping. This plan consists in the formulation of the research questions, selection of the sources of primary studies, and establishment of the inclusion and exclusion criteria.

(i) Research Questions (RQ): These questions are structured corresponding to the objective that is intended with the systematic mapping that, in our case, it is the identification of a panorama involving UML extensions to model aspect-oriented software systems. The research questions of our systematic mapping are:

RQ1: Which UML techniques have been applied to model aspect-oriented software systems?

RQ2: Which are the terms (word or set of words) that are often associated with work that investigate UML extension to represent aspect-oriented software systems?

RQ3: Which vehicles have more published work on UML extensions to model aspect-oriented software systems?

RQ4: Which are the research groups that have investigated UML extensions to represent aspect-oriented software systems?

\section{(ii) Selection of Sources:}

In addition to the research questions, we established which search sources (i.e., publication databases) would be used to find the primary studies. The criteria used to select the sources were: content update (publications are regularly updated); availability (full text of the papers are available); quality of results (accuracy of the results returned by the search); and versatility export (since much information are returned through the search, a mechanism to export the results is required). These criteria are also discussed in [8]. Thus, the selected databases to our systematic mapping are shown in Table 1. According to Brereton et al. [3, 10] and Dybå et al. [10], these databases are efficient to conduct systematic mapping in the context of software engineering. Furthermore, Scopus was added, since it is considered the largest database of abstracts and citations [16]. 
CLEI ELECTRONIC JOURNAL VOLUME 14 NUMBER 1 PAPER 3 APRIL 2011

Table 1: Selected Databases

\begin{tabular}{ll}
\hline Database & Location \\
\hline ACM Digital Library & www.portal.acm.org \\
IEEE Xplore & www.ieexplore.ieee.org \\
ScienceDirect & www.sciencedirect.com \\
Scopus & www.scopus.com \\
ISI Web of Science & www.isiknowledge.com \\
\hline
\end{tabular}

(iii) Establishment of Selection Criteria: Another important element of the systematic mapping planning is to define the Inclusion Criteria (IC) and Exclusion Criteria (EC). These criteria make possible to include primary studies that are relevant to answer the research questions and exclude studies that do not answer them. Thus, the inclusion criteria of our systematic mapping are shown in Table 2 and the exclusion criteria are shown in Table 3.

Table 2: Inclusion criteria established for the systematic mapping

\begin{tabular}{ll}
\hline Id & Criteria \\
\hline IC1 & The primary study proposes UML extensions to represent aspect-oriented software systems \\
IC2 & $\begin{array}{l}\text { The primary study proposes the use of UML techniques to represent aspect-oriented software } \\
\text { systems } \\
\text { TC3 }\end{array}$ \\
& $\begin{array}{l}\text { The primary study proposes a tool to support UML techniques to represent aspect-oriented } \\
\text { software systems }\end{array}$ \\
\hline
\end{tabular}

Table 3: Exclusion criteria established for the systematic mapping

\begin{tabular}{ll}
\hline Id & Criteria \\
\hline EC1 & The primary study does not address modeling of aspect-oriented software systems \\
EC2 & The primary study is not related to UML \\
EC3 & The primary study proposes a new language to model aspect-oriented software systems \\
EC4 & The primary study does not present any abstract or it is not available for further reading \\
EC5 & The primary study is written in a different language than English \\
EC6 & The primary study presents an abstract and an introductory section that seem related to UML \\
& extensions to model aspect-oriented software systems; however, the rest of the text is not in \\
& fact related to \\
EC7 & The primary study is directly related to another primary study of the same author \\
EC8 & The primary study consists of a compilation of work, for instance, from a conference or \\
& workshop
\end{tabular}

\subsection{Step 2: Conduction of the Search}

In this step, the search by primary studies is conducted according to previously established plan. This search is done by looking for all primary studies that match with the search string in the search sources. This can be automatically conducted if these sources provide an efficient search engine. For this, we established the keywords and the search strings.

(i) Keywords: To keep the scope of the systematic mapping, the keywords must be simple and well chosen. Thus, they must be simple enough to bring many results and also rigorous enough to cover only the desired primary studies. The keywords chosen to our systematic mapping are: UML, aspect based, aspect-oriented, and aspect-oriented modeling.

(ii) Search Strings: Based on the keywords, the search string is built (through connections AND/OR) to incorporate the semantic expected to the search. The search string used in our systematic mapping was: 
CLEI ELECTRONIC JOURNAL VOLUME 14 NUMBER 1 PAPER 3 APRIL 2011

(UML AND ("aspect-based" OR "aspect oriented" OR "aspect-oriented" OR AOM OR "aspect oriented modeling" OR "aspect-oriented modeling")

We have also built the strings and/or settings for each search engine, since each engine accepts a specific formatted. In Table 4, it is presented these strings and settings.

Table 4: Search Strings by Source

\begin{tabular}{|c|c|}
\hline Source & Search String \\
\hline ACM Digital Library & $\begin{array}{l}\text { (Title:(uml AND (aspect-based OR aspect-oriented OR "aspect oriented" OR "aspect ori- } \\
\text { ented modeling" OR aom OR "aspect-oriented modeling")) OR Keywords:(uml AND } \\
\text { (aspect-based OR aspect-oriented OR "aspect oriented" OR "aspect oriented model- } \\
\text { ing" OR aom OR "aspect-oriented modeling")) OR Abstract:(uml AND (aspect-based } \\
\text { OR aspect-oriented OR "aspect oriented" OR "aspect oriented modeling" OR aom OR } \\
\text { "aspect-oriented modeling"))) }\end{array}$ \\
\hline IEEE Xplore & $\begin{array}{l}((\text { uml }<\text { and }>(\text { aspect-based }<\text { or }>\text { aspect-oriented }<\text { or }>\text { 'aspect oriented' }<\text { or }>\text { 'aspect } \\
\text { oriented modeling' }<\text { or }>\text { aom }<\text { or }>\text { 'aspect-oriented modeling') })<\text { in }>\text { ti })<\text { or }>((\text { uml } \\
<\text { and }>(\text { aspect-based }<\text { or }>\text { aspect-oriented }<\text { or }>\text { 'aspect oriented' }<\text { or }>\text { 'aspect ori- } \\
\text { ented modeling' }<\text { or }>\text { aom }<\text { or }>\text { 'aspect-oriented modeling') }<<\text { in }>\text { ab })\end{array}$ \\
\hline ScienceDirect & $\begin{array}{l}\text { TITLE-ABSTR-KEY((uml AND (aspect-based OR aspect-oriented OR aspect oriented } \\
\text { OR aspect oriented modeling OR aom OR aspect-oriented modeling))) }\end{array}$ \\
\hline Scopus & $\begin{array}{l}\text { TITLE-ABS-KEY(uml AND (aspect-based OR aspect-oriented OR "aspect oriented" OR } \\
\text { "aspect oriented modeling" OR aom OR "aspect-oriented modeling”)) AND (LIMITTO( } \\
\text { SUBJAREA, "COMP") OR LIMIT-TO(SUBJAREA, "MULT")) }\end{array}$ \\
\hline ISI Web of Science & $\begin{array}{l}\text { TI=((uml AND (aspect-based OR aspect-oriented OR "aspect oriented" OR "aspect ori- } \\
\text { ented modeling" OR aom OR "aspect-oriented modeling")) OR TS = ((uml AND (aspect- } \\
\text { based OR aspect-oriented OR "aspect oriented" OR "aspect oriented modeling" OR aom } \\
\text { OR "aspect-oriented modeling")) }\end{array}$ \\
\hline
\end{tabular}

As result of this step, we obtained a total of 593 primary studies: 118 from ACM Digital Library, 69 from IEEE Xplore, 67 from ScienceDirect, 119 from ISI Web of Science and 220 from Scopus. Figure 2 shows the distribution of these studies into the web search engines selected.

\subsection{Step 3: Selection of the Primary Studies}

In this step, the selection criteria (i.e., inclusion and exclusion criteria) are applied to select the relevant primary studies. To support the organization and manipulation of the primary studies, we used JabRef ${ }^{1}$, an open source reference manager system. It made possible to store information on the primary studies (including, for instance, title, authors, and abstract), as well as the inclusion/exclusion criteria applied to select each primary study.

From 593 primary studies, 268 were repeated. Thus, we found 325 different studies. Applying our selection criteria, we included then 84 primary studies ${ }^{2}$. Table 5 summarizes the total of primary studies obtained in each database, the number of studies included (or selected), the precision rate ${ }^{3}$, the rate index ${ }^{4}$, and the search date. For instance, from ACM Digital Library, we obtained a total of 118 studies; using the selection criteria, 50 studies were selected; precision rate is $42 \%$ (i.e.,

\footnotetext{
${ }^{1}$ http://jabref.sourceforge.net/

${ }^{2}$ The complete reference of each primary study included can be found in the Appendix A.

${ }^{3}$ Ratio between the total of included studies of a database and the total of primary studies obtained by this database.

${ }^{4}$ Ratio between the included studies of a database and the total of primary studies included in the systematic review.
} 


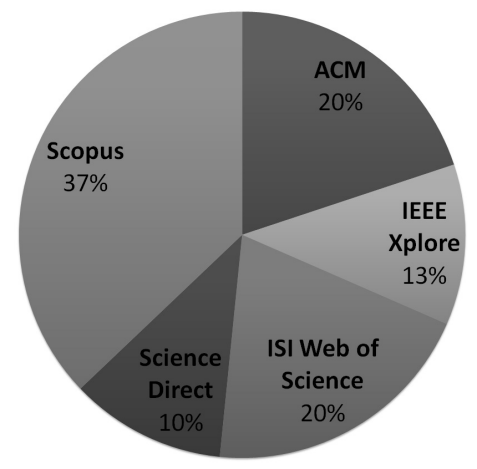

Figure 2: Distribution of the primary studies obtained

50/118) and rate index is $60 \%$ (i.e., 50/84). It is important to observe that Scopus was the most efficient source, since $75 \%$ of all included papers were obtained in this source. Otherwise, ScienceDirect contributed with only $2 \%$ of primary studies which were also indexed by other sources. Therefore, we can point out that if there is an interest in searching work that involve the research topic of this work (i.e., UML extensions to model aspect-oriented software systems), searches using Scopus and ACM Digital Library could cover almost all work of this topic. In other words, Scopus obtained $75 \%$ and ACM Digital Library obtained 60\%. Since Scopus indexes also studies of other databases, such as IEEE Xplore and ACM Digital Library, if the search was concentrated only in these two database (Scopus and ACM Digital Library), we would find $94 \%$ of the primary studies that we have selected.

Table 5: Search sources, obtained and included primary studies

\begin{tabular}{llllll}
\hline Database & Obtained & Included & Precision Rate & Rate Index & Date \\
\hline ACM Digital Library & 118 & 50 & $42 \%$ & $60 \%$ & Feb 5,2011 \\
IEEE Xplore & 69 & 34 & $49 \%$ & $40 \%$ & Feb 5,2011 \\
ISI Web of Science & 119 & 40 & $34 \%$ & $48 \%$ & Feb 5,2011 \\
ScienceDirect & 67 & 2 & $3 \%$ & $2 \%$ & Feb 5,2011 \\
Scopus & 220 & 63 & $29 \%$ & $75 \%$ & Feb 5,2011 \\
\hline
\end{tabular}

Figure 3 presents the amount of primary studies included as relevant and separated by years. It is observed a strong growth of publications in the last years, mainly in Scopus and ACM Digital Library. Other sources (IEEE Xplore and ISI Web of Science) have what might be called an expected growth, considering the other two most numerous sources (Scopus and ACM Digital Library).

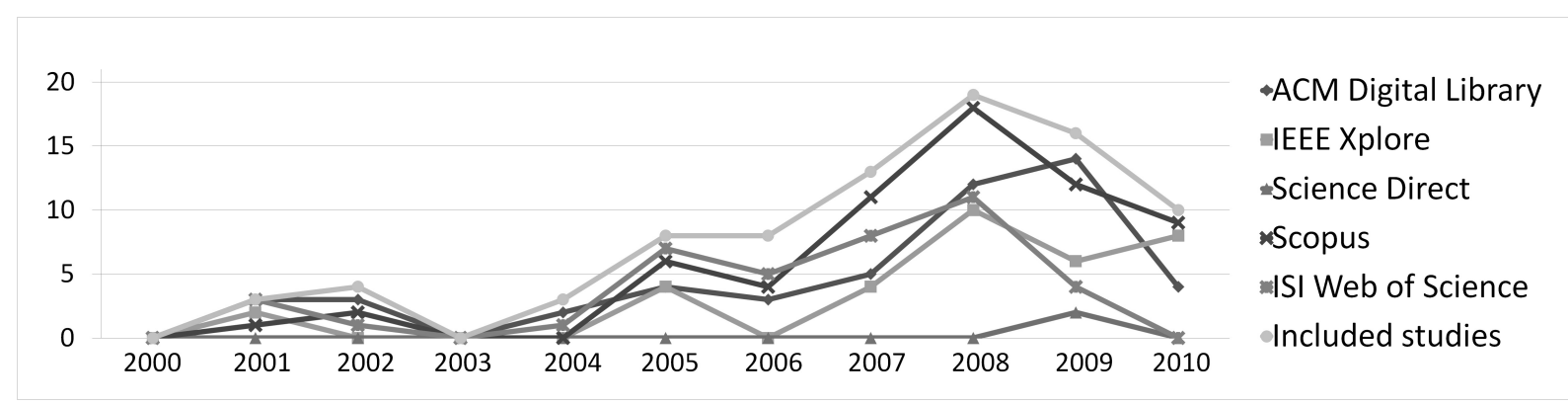

Figure 3: Amount of included primary studies 


\subsection{Step 4: Analysis, Classification and Map Building}

While in previous section we present a more quantitative analysis of our systematic mapping, in this section, we present the categorization of the primary studies. For this, two tasks were conducted: (i) search by keywords; and (ii) grouping of the primary studies into categories. Thus, primary studies were firstly carefully read (i.e., title, keywords, and abstract). Next task was the creation of categories. For this, research questions were considered. In the case of our systematic mapping, we were interested in identifying ways of applying UML techniques to model aspect-oriented systems. Thus, four categories were created:

UML Diagrams to Represent Aspect-oriented Software Systems: The keywords used in this category refer to the UML techniques (version 2.2): Use Case Diagram, State Machine Diagram, Timing Diagram, Interaction Overview Diagram, Communication Diagram, Sequence Diagram, Activity Diagram, Profile Diagram, Composite Structure Diagram, Package Diagram, Deployment Diagram, Component Diagram, Class Diagram, and Object Diagram. We are interested in knowing which UML techniques have been more investigated to model aspect-oriented software systems;

Main Keywords: Keywords of this category refer to the most relevant keywords obtained from the selected primary studies. To do this, we firstly identified all the keywords from studies included. Then, these keywords were classified according to their frequency of occurrence. Finally, we selected the keywords that seemed more relevant or referred to software engineering research areas;

Main Events and Journals: Keywords of this category refer to name of the events (such as conference and workshop) and journals in which the included primary studies were published; and

Main Research Groups: Keywords of this category refer to the research groups that have published work related to UML extension to model aspect-oriented software systems. For this, we firstly identified all research groups related to included primary studies identified in our mapping. Then, research groups that had two or more primary studies (that were included in our mapping) were chosen as keywords of this category.

Following, we classified the primary studies into keywords in the categories. It is observed that a study can be classified sometimes into more than one keyword per category. Moreover, for category "UML Diagrams to Represent Aspectoriented Systems", we read all relevant primary studies and separated them among the keywords. The same strategy was conduced to other three category: "Main Keywords", "Main Events and Journal", and "Main Research Groups". As result, we build four maps, one for each category.

Figure 4 shows the map to the category "UML Diagrams to Represent Aspect-oriented Systems". The reader can refer to Appendix $\mathrm{C}$ in order to find the complete list of primary studies classified in each category established for this map. It is observed that from first studies in 2001, there is an increasing interest in extending UML diagrams to model aspect-oriented software systems. It is important to notice that there is an overlap between Class Diagram and Profile Diagram ${ }^{5}$, since primary studies extend the Class Diagram using new stereotypes, such as $\langle<$ aspect $\rangle>$ and $\langle<$ crosscuts $\rangle>$, that are specific to aspect-oriented systems. Among the behavioral diagrams, Sequence Diagram and State Machine Diagram have been more investigated to represent aspect-oriented systems. These diagrams make possible to describe new behaviors introduced by the aspects and represent more easily when and how these aspects will be executed. Otherwise, diagrams that are not so disseminated and used (for example, Timing Diagram, Interaction Overview Diagram, and Composite Structure Diagram) if compared with, for instance, Class Diagram, have not been considered to model aspect-oriented systems.

Figure 5 shows the map to the category "Main Keywords". The keywords of this category are: Aspect Composition, Case Study, Component, Composition Mechanism, Framework, Join Point Model, Model-driven Architecture, Model-driven Development, Requirement, Reverse Engineering, Software Architecture, Tool Support, UML Based, UML Extension, UML Profile, and UML Standard. The reader can refer to Appendix $C$ in order to find the complete list of primary studies

\footnotetext{
${ }^{5}$ Profile Diagram allows to define custom stereotypes, tag definitions, and constraints in a UML diagram.
} 


\section{CLEI ELECTRONIC JOURNAL VOLUME 14 NUMBER 1 PAPER 3 APRIL 2011}

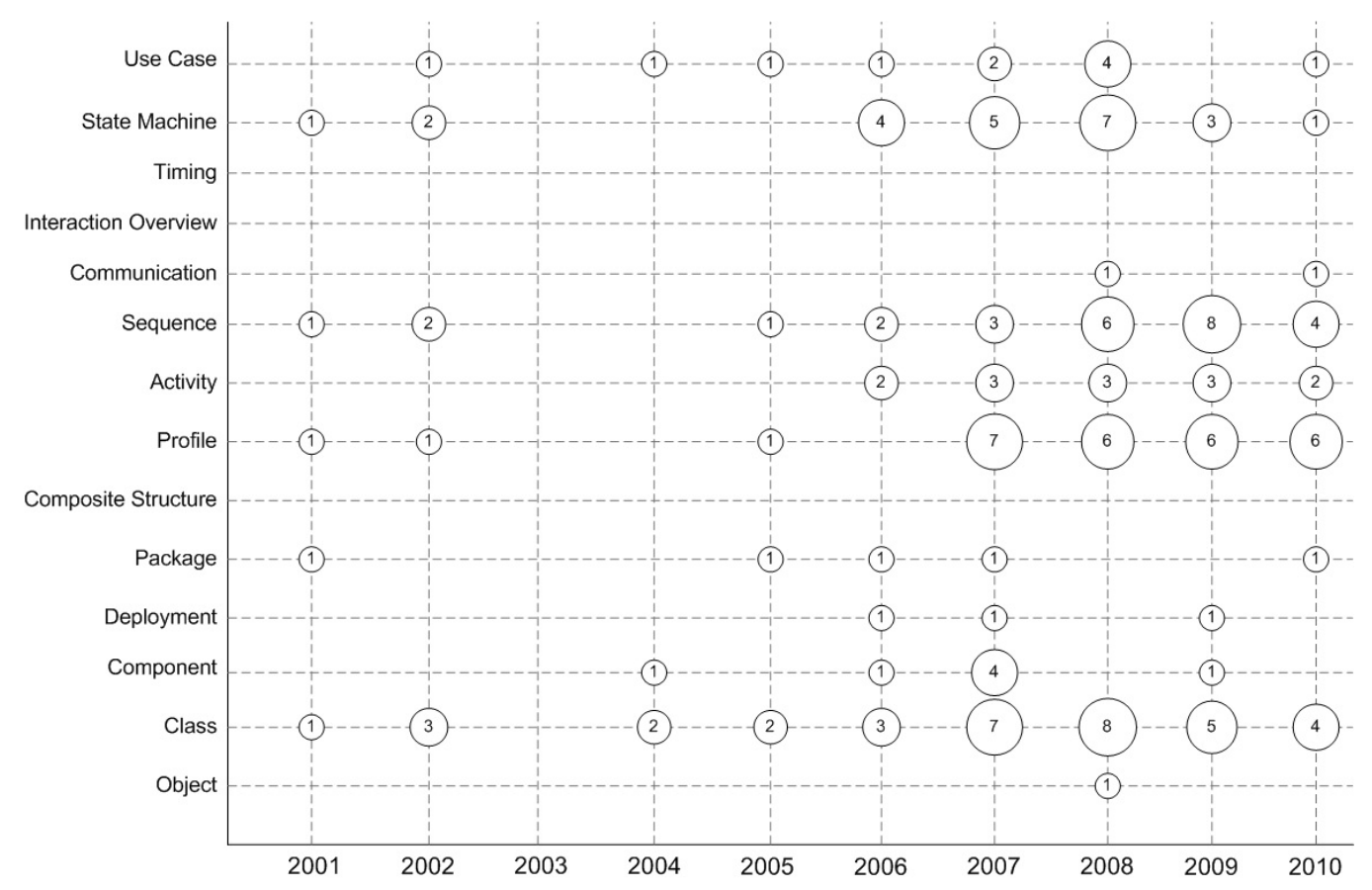

Figure 4: Map related to category "UML Diagrams to represent aspect-oriented systems"

classified in each category established for this map. This map shows which are the keywords that are more directly related to work that extend UML to model aspect-oriented systems. Thus, for instance, the keywords "UML extension" and "UML Based" are two important keywords that could be used in the future searches for primary studies. Otherwise, only few primary studies on UML extension to aspect-orientation domain are related to "Requirements" and "Reverse Engineering".

Figure $6^{6}$ shows the map to the category "Main Events and Journals". The keywords of this category are events and journals in which the 84 primary studies selected in our mapping were published. It is important to notice that the primary studies were published in a diversity of events and journal (51 different events and 7 journals). Furthermore, these studies are not only concentrate in well-known events or those specific of aspect-orientation, such as ICSE (ACM/IEEE International Conference on Software Engineering) and $\mathrm{AOSD}^{7}$ (International Conference on Aspect-Oriented Software Development). Therefore, if the search space was limited to those more known events and journals, important and relevant primary studies could not be found. For instance, AOSD published three primary studies and ICSE published only one among our 84 studies. Thus, systematic mapping was a fundamental and important technique to conduct our search and achieve positive and more extensive result.

Figure 7 shows the map to the category "Main Research Groups". For the sake of space, only research groups that published two or more studies were considered. Therefore, 19 research groups were considered in this map. For instance, research group of the Hebei University of Engineering (in China) published seven primary studies and each one of them deals with one UML diagram: Sequence Diagram, State Machine Diagram, Class Diagram, and in the design of connectors to represent aspect-oriented components. There is also an effort in applying these concepts in the framework of MDA (Model Driven Architecture). Meanwhile, other research groups in 17 universities published two or three studies. Furthermore, it is worth to highlighting that we identified other 59 different institutions that have published only one primary study. Therefore, we have observed that researches involving UML extension to aspect-orientation domain have been conducted by many different institutions.

\footnotetext{
${ }^{6}$ The meaning of the abbreviations can be found in the Appendix B.

${ }^{7}$ http://www. aosd.net/
} 


\section{CLEI ELECTRONIC JOURNAL VOLUME 14 NUMBER 1 PAPER 3 APRIL 2011}

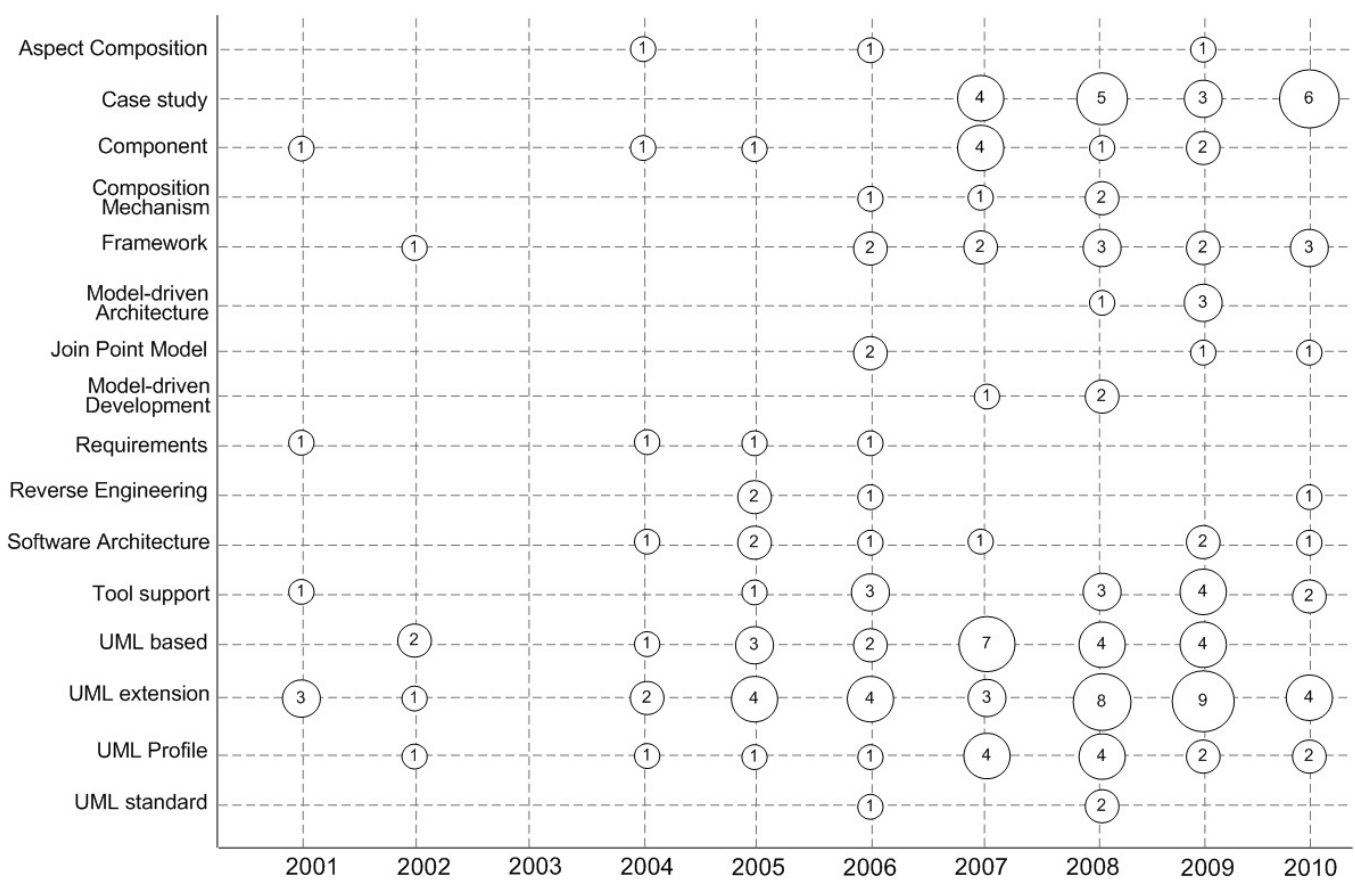

Figure 5: Map related to category "Main Keywords"

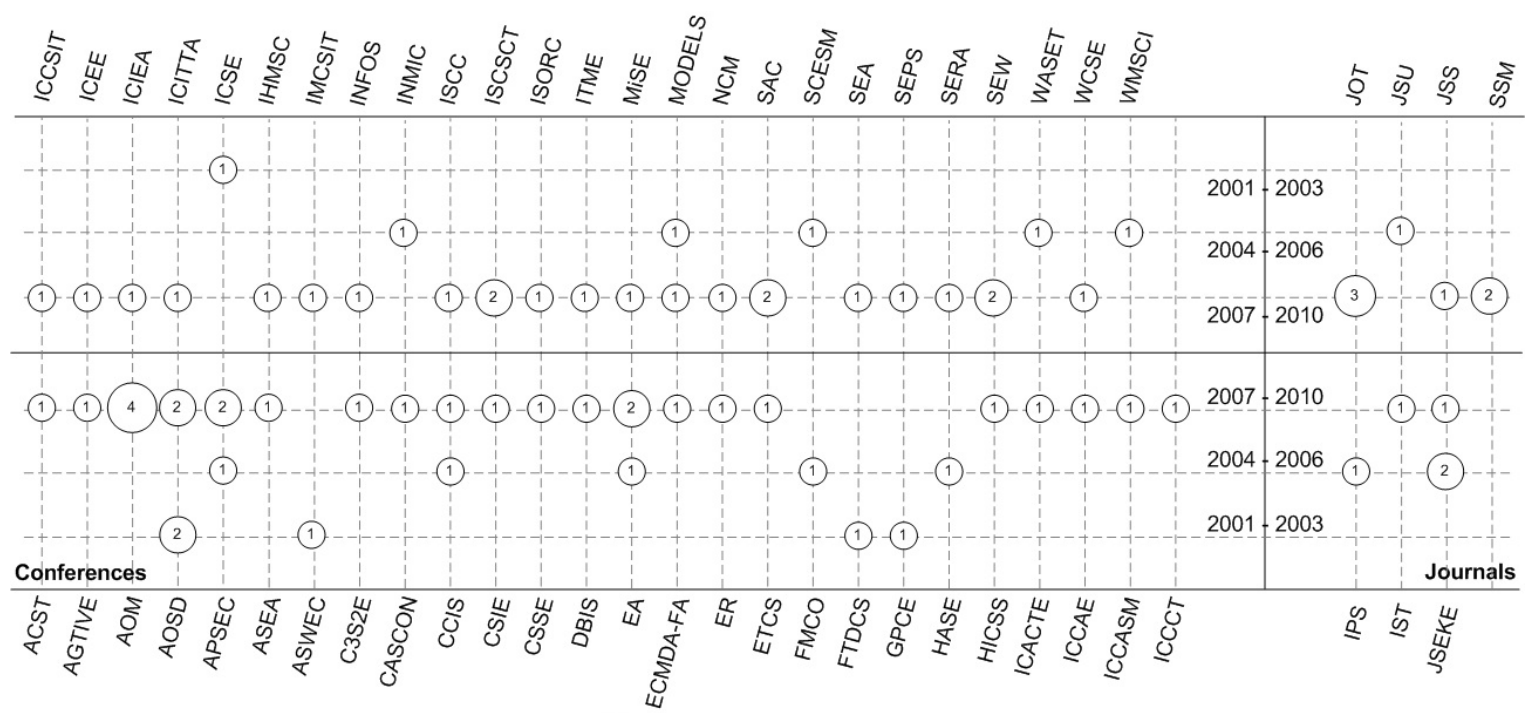

Figure 6: Map related to category "Main Events and Journals"

\section{Discussion}

In this section, we discuss some issues related to the conducted systematic mapping, what also includes lessons learned and limitations we have noticed.

Regarding research questions established for our systematic mapping, it is observed that all of them were successfully answered. This suggests that, the general knowledge about representing aspect-oriented systems using UML techniques has been mapped. Besides that, we believe that results presented in this work are representative of the whole universe of 
CLEI ELECTRONIC JOURNAL VOLUME 14 NUMBER 1 PAPER 3 APRIL 2011

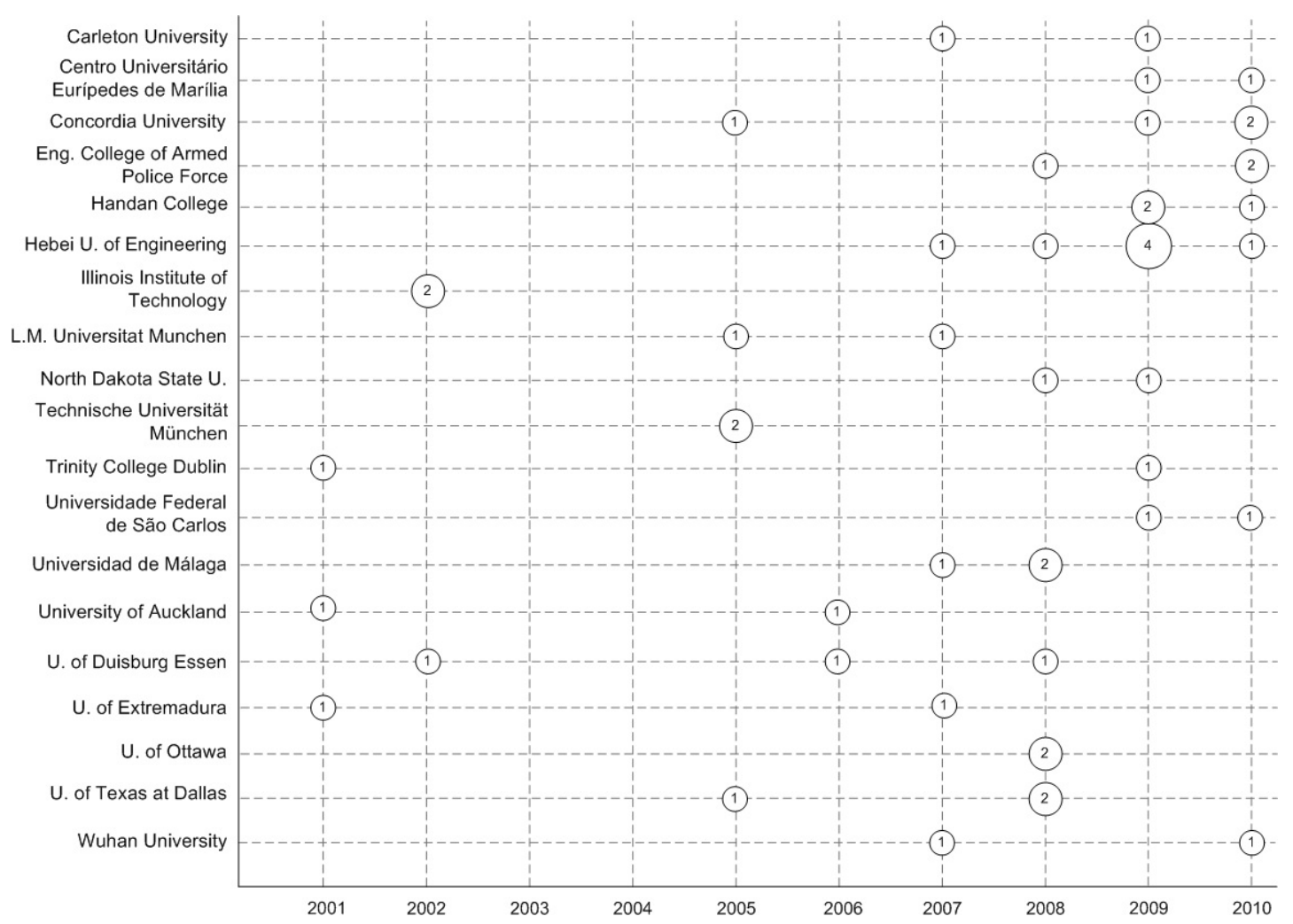

Figure 7: Map related to category "Main Research Groups"

existing approaches to model aspect-oriented systems, since systematic mapping has provide mechanism to achieve it.

Considering knowledge arisen from this work, it is possible to identify interesting and important research lines that can be investigated in future work. For instance, the establishment of a unified UML notation to aspect-oriented modeling and extension of UML diagram that have not been explored in aspect-orientation domain, such as Timing Diagram.

Regarding limitation of this work, other categories could have beeb established and, as a consequence, related maps could have been designed. In another perspective, other research questions could be established, considering specific topics of research. Moreover, it is worth highlighting that systematic mapping conduction is not a trivial task because the amount of papers that need to be manipulated. Besides that, both paper reading and category analysis are manually conducted. Many of the studies provided none substantial information in the abstract or representative keywords to facilitate the analysis phase of the mapping. In those cases, it was also necessary to read the introduction and conclusion sections and, sometimes, the entire text of the primary study to determine the context and contributions of the study. Sometimes it was necessary to infer a conclusion to make some decisions. Besides that, during the conduction of our systematic mapping, more specifically after the primary studies had already been selected for our mapping, IEEE Xplore changed its search engine. Thus, the results presented here might be different from those obtained if a new search is conducted in that database.

\section{Conclusions}

The main contribution of this work was to present an overview about UML extensions to represent aspect-oriented software systems. To establish this overview, it was essential to systematically apply the set of steps provided by systematic mapping. As results, we found that there are several initiatives being proposed aiming at extending UML for the aspectorientation approach. It is also important to notice that most studies were published in the last four years. In spite of that, 
there is a lack of consensus about which extensions should be disseminated and more widely used. Thus, we believe that this overview can contribute to the aspect-oriented software development area, getting new lines of research that are open yet. Besides that, in the same perspective, other mappings must be conduced, what could contribute to the establishment of a unified solution to the aspect-oriented modeling.

Acknowledgments This work is supported by Brazilian funding agencies: FAPESP, CAPES, and CNPq.

\section{References}

[1] R. Afzal, W.; Torkar and R. Feldt, "A systematic mapping study on non-functional search-based software testing," in Proceedings of the $20^{\text {th }}$ International Conference on Software Engineering and Knowledge Engineering (SEKE 2008), San Francisco, USA, 2008, pp. 1-6.

[2] E. Baniassad, P. C. Clements, J. Araujo, A. Moreira, A. Rashid, and B. Tekinerdogan, "Discovering early aspects," IEEE Software, vol. 23, no. 1, pp. 61-70, 2006.

[3] P. Brereton, B. A. Kitchenham, D. Budgen, M. Turner, and M. Khalil, "Lessons from applying the systematic literature review process within the software engineering domain," Journal of Systems and Software, vol. 80, no. 4, pp. 571-583, 2007.

[4] M. B. P. Budgen, D.; Turner and B. Kitchenham, "Using mapping studies in software engineering," in Proceedings of the $20^{\text {th }}$ Annual Meeting of the Psychology of Programming Interest Group (PPIG 2008), Lancaster, United Kingdom, 2008, pp. 195-204.

[5] S. Clarke and E. Baniassad, Aspect-Oriented Analysis and Design: The Theme Approach, ser. Object Technology, 2005.

[6] N. Condori-Fernandez, M. Daneva, K. Sikkel, R. Wieringa, O. Dieste, and O. Pastor, "A systematic mapping study on empirical evaluation of software requirements specifications techniques," in Proceedings of the $3^{\text {rd }}$ International Symposium on Empirical Software Engineering and Measurement (ESEM 2009), Lake Buena Vista, USA, 2009, pp. 502-505.

[7] W. L. L. X. Cui, Z. and D. Xu, "Modeling and integrating aspects with UML activity diagrams," in Proceedings of the 2009 ACM Symposium on Applied Computing (SAC 2009), New York, USA, 2009, pp. 403-437.

[8] O. Dieste, A. Grimán, and N. Juristo, "Developing search strategies for detecting relevant experiments," Empirical Software Engineering, vol. 14, no. 5, pp. 513-539, 2009.

[9] T. Dybå, B. Kitchenham, and M. Jorgensen, "Evidence-based software engineering for practitioners," IEEE Software, vol. 22, no. 1, pp. 58-65, 2005.

[10] T. Dybå, T. Dingsoyr, and G. K. Hanssen, "Applying systematic reviews to diverse study types: An experience report," in Proceedings of the $1^{\text {st }}$ International Symposium on Empirical Software Engineering and Measurement (ESEM 2007), Los Alamitos, USA, 2007, pp. 225-234.

[11] M. Guessi, L. B. R. Oliveira, and E. Y. Nakagawa, "Modeling Aspect-oriented Software Systems Using UML: A Systematic Mapping," in Proceedings of the $36^{\text {th }}$ Latin American Conference of Informatics (CLEI 2010), Asuncion, Paraguay, 2010, pp. 1-14.

[12] J. Ivers, P. Clements, D. Garlan, R. Nord, B. Schmerl, and J. R. O. Silva, "Documenting component and connector views with UML 2.0,” Tech. Rep., 2004, cMU/SEI-2004-TR-008.

[13] S. A. Khan and A. Nadeem, "UML Extensions for Modeling Aspect Oriented Software: A Survey," in Proceedings of the National Software Engineering Conference (NSEC 2010), Rawalpindi, Pakistan, 2010, pp. 1-6. 
[14] G. Kiczales, J. Irwin, J. Lamping, J. Loingtier, C. Lopes, C. Maeda, and A. Menhdhekar, "Aspect-oriented programming," in Proceedings of the $11^{\text {th }}$ European Conference on Object-Oriented Programming (ECOOP 1997), Jyväskylä, Finland, 1997, pp. 220-242.

[15] B. Kitchenham, "Procedures for performing systematic reviews," Keele University and National ICT Australia Ltd, Tech. Rep. TR/SE-0401 and NICTA Technical Report 0400011T.1, 2004.

[16] B. Kitchenham and S. Charters, "Guidelines for performing systematic literature reviews in software engineering," Keele University and Durham University Joint Report, Tech. Rep. EBSE 2007-001, 2007. [Online]. Available: http://www.dur.ac.uk/ebse/resources/Systematic-reviews-5-8.pdf

[17] R. Laddad, “Aspect-oriented programming will improve quality,” IEEE Software, vol. 20, no. 6, pp. 90-91, 2003.

[18] Y. Lau, W. Zhao, X. Peng, Y. Chen, and Z. Jiang, "A unified formal model for supporting aspect-oriented dynamic software architecture," in Proceedings of the International Conference on Convergence Information Technology (ICCIT 2007), Los Alamitos, USA, 2007, pp. 450-455.

[19] E. Navarro, P. Letelier, and I. Ramos, "Requirements and scenarios: Running aspect-oriented software architectures," in Proceedings of the $6^{\text {th }}$ Working IEEE/IFIP Conference on Software Architecture (WICSA 2007), Mumbai, India, 2007, p. 23.

[20] OMG, "Unified modeling language version 2.2," [Online], 2009, Available:http://www.omg.org/spec/UML/2.2/.

[21] V. Paula and T. Batista, "Revisiting a formal framework for modeling aspects in the design phase," in Proceedings of the Early Aspects at ICSE: Workshops in Aspect-Oriented Requirements Engineering and Architecture Design, Washington, DC, USA, 2007, p. 6.

[22] K. Petersen, R. Feldt, M. Shahid, and M. Mattsson, "Systematic mapping studies in software engineering," in Proceedings of the $5^{\text {th }}$ IEEE Workshop on Engineering of Autonomic and Autonomous Systems (EASe 2008), Belfast, Northern Ireland, 2008, pp. 1-10.

[23] M. Pinto, N. Gamez, and L. Fuentes, "Towards the architectural definition of the health watcher system with AOADL," in Proceedings of the Early Aspects at ICSE: Workshops in Aspect-Oriented Requirements Engineering and Architecture Design, Washington, DC, USA, 2007, p. 5. 


\section{CLEI ELECTRONIC JOURNAL VOLUME 14 NUMBER 1 PAPER 3 APRIL 2011}

\section{Appendix A}

Table 6 presents the complete reference of each primary study included in the systematic mapping.

Table 6: Complete reference of primary studies included

\begin{tabular}{|c|c|}
\hline Id & Reference \\
\hline S1 & $\begin{array}{l}\text { Abeywickrama, D. \& Ramakrishnan, S., "Towards engineering models of aspectual pervasive software services", In Proceedings of the } \\
\text { 3rd ACM workshop on Software engineering for pervasive services (SEPS 2008), 2008, pp. 3-8, Sorrento, Italy. }\end{array}$ \\
\hline $\mathrm{S} 2$ & $\begin{array}{l}\text { Alam, F. E., Evermann, J. \& Fiech, A., "Modeling for dynamic aspect-oriented development", In Proceedings of the 2nd Canadian } \\
\text { Conference on Computer Science and Software Engineering (C3S2E 2009), 2009, pp. 143-147, Montreal, Canada. }\end{array}$ \\
\hline S3 & $\begin{array}{l}\text { Albunni, N. \& Petridis, M., "Using UML for Modelling Cross-Cutting Concerns in Aspect Oriented Software Engineering". In Proceedings } \\
\text { of the 3rd International Conference on Information and Communication Technologies: From Theory to Applications (ICTTA 2008), 2008, } \\
\text { pp. 1-6, Damascus, Syria. }\end{array}$ \\
\hline S4 & Aldawud, O. M., "Aspect-oriented modeling with UML”, PhD thesis, Illinois Institute of Technology, 2002, Chicago. \\
\hline S5 & $\begin{array}{l}\text { Anthonysamy, P. \& Somé, S., "Aspect-oriented use case modeling for software product lines", In Proceedings of the } 2008 \text { AOSD workshop } \\
\text { on Early aspects (EA-AOSD 2008), 2008, pp. 1-8, Brussels, Belgium. }\end{array}$ \\
\hline S6 & $\begin{array}{l}\text { Ballal, R. \& Hoffman, M. A., "Extending UML for Aspect Oriented Software Modeling", In Proceedings of the WRI World Congress on } \\
\text { Computer Science and Information Engineering (CSIE 2009), 2009, volume 7, pp. 488-492, Cayro, Egypt. }\end{array}$ \\
\hline S7 & $\begin{array}{l}\text { Bustos, A. \& Eterovic, Y., "Modeling aspects with UML's class, sequence and state diagrams in an industrial setting", In Proceedings of } \\
\text { the 11th IASTED International Conference on Software Engineering and Applications (SEA 2007), 2007, pp. 403-410, Anaheim, USA. }\end{array}$ \\
\hline S8 & $\begin{array}{l}\text { Carton, A., Driver, C., Jackson, A. \& Clarke, S., "Model-Driven Theme/UML", In Transactions on Aspect-Oriented Software Development } \\
\text { VI, 2009, pp. 238-266 (LNCS v.5560), Berlin, Heidelberg. }\end{array}$ \\
\hline S9 & Clarke, S. \& Baniassad, E., "Aspect-Oriented Analysis and Design”, Addison-Wesley Professional, 2005. \\
\hline S10 & $\begin{array}{l}\text { Clarke, S. \& Walker, R., "Composition patterns: An approach to designing reusable aspects", In Proceedings of the 23rd International } \\
\text { Conference on Software Engineering (ICSE 2001), 2001, pp. 5-14, Toronto, Canada. }\end{array}$ \\
\hline S11 & $\begin{array}{l}\text { Clemente, P. J., Hernandez, J. \& Sanchez, F., "Driving Component Composition from Early Stages Using Aspect-Oriented Techniques", } \\
\text { In Proceedings of the 40th Annual Hawaii International Conference on System Sciences (HICSS 2007), 2007, pp. 257a, Big Island, USA. }\end{array}$ \\
\hline S12 & $\begin{array}{l}\text { Cui, Z., Wang, L., Li, X. \& Xu, D., "Modeling and integrating aspects with UML activity diagrams", In Proceedings of the } 24 \text { th ACM } \\
\text { symposium on Applied Computing (SAC 2009), 2009, pp. 430-437, Honolulu, USA. }\end{array}$ \\
\hline S13 & $\begin{array}{l}\text { Dai, L., Cooper, K. \& Eric Wong, W., "Modeling and analysis of performance aspects for software architecture: A UML-based approach", } \\
\text { International Journal of Software Engineering and Knowledge Engineering (IJSEKE), 2006, 16(3):347-378. }\end{array}$ \\
\hline S14 & $\begin{array}{l}\text { Debnath, N., Baigorria, L., Riesco, D. \& Montejano, G., "Metrics applied to Aspect Oriented Design using UML profiles", In IEEE } \\
\text { Symposium on Computers and Communications (ISCC 2008), 2008, 654-657, Marrakech, Morocco. }\end{array}$ \\
\hline S15 & $\begin{array}{l}\text { Deng, Z. \& Xu, X., "Aspect-oriented Technology-Based Production System Simulation Modeling Method", In Proceedings of the } 2010 \\
\text { International Conference on E-Business and E-Government (ICEE 2010), 2010 }\end{array}$ \\
\hline S16 & $\begin{array}{l}\text { Deubler, M., Meisinger, M., Rittmann, S. \& Kruger, I., "Modeling crosscutting services with UML sequence diagrams", In Proceedings } \\
\text { of the 8th International Conference on Model Driven Engineering Languages and Systems (MODELS 2005), 2005, pp. 522-536 (LNCS } \\
\text { v.3713), Montego Bay, Jamaica. }\end{array}$ \\
\hline S17 & $\begin{array}{l}\text { Domokos, P. \& Majzik, I., "Design and Analysis of Fault Tolerant Architectures by Model Weaving", In Proceedings of the 9th IEEE } \\
\text { International Symposium on High-Assurance Systems Engineering (HASE 2005), 2005, pp. 15-24, Heidelberg, Germany. }\end{array}$ \\
\hline S18 & $\begin{array}{l}\text { El Maghawry, N. \& Dawood, A., "Aspect oriented GoF design patterns", In Proceesings of the 7th International Conference on Informatics } \\
\text { and Systems (INFOS 2010), 2010, pp. 1-7, Cairo, Egypt. }\end{array}$ \\
\hline S19 & $\begin{array}{l}\text { Elrad, T.,; Aldawud, O. \& Bader, A., "Aspect-oriented modeling: Bridging the gap between implementation and design", In Proceedings } \\
\text { of the 1st International Conference on Generative Programming and Component Engineering (GPCE 2002), 2002, pp. 189-201 (LNCS } \\
\text { v.2487) }\end{array}$ \\
\hline S20 & Evermann, J., "A meta-level specification and profile for AspectJ in UML”, Journal of Object Technology (JOT), 2007, 6(7):27-49. \\
\hline $\mathrm{S} 21$ & Filman, R., Elrad, T., Clarke, S. \& Akşit, M. Aspect-oriented software development, Addison-Wesley Professional, 2004 \\
\hline S22 & $\begin{array}{l}\text { Foumani, A. A. \& Constantinides, C., "Aspect-oriented reverse engineering", In Proceedings of the 9th World Multi-Conference on Sys- } \\
\text { temics, Cybernetics and Informatics (WMSCI 2005), 2005, volume 1, pp. 253-260, Int. Inst. of Informatics \& Systemics. }\end{array}$ \\
\hline S23 & $\begin{array}{l}\text { France, R., Ray, I., Georg, G. \& Ghosh, S., "Aspect-oriented approach to early design modelling", IEE Proceedings Software (IPE), } \\
\text { 151(4):173-185. }\end{array}$ \\
\hline S24 & $\begin{array}{l}\text { Fuentes, L., Manrique, J. \& Sánchez, P., "Execution and simulation of (profiled) UML models using Pópulo", In Workshop on Modeling } \\
\text { in Software Engineering (MiSE 2008), 30th International Conference on Software Engineering (ICSE 2008), 2008, pp. 75-81, Leipzig, } \\
\text { Germany. }\end{array}$ \\
\hline S25 & $\begin{array}{l}\text { Fuentes, L. \& Sánchez, P., "Designing and weaving Aspect-Oriented executable UML models", Journal of Object Technology (JOT), } \\
6(7): 109-136 .\end{array}$ \\
\hline
\end{tabular}

Continued... 


\section{CLEI ELECTRONIC JOURNAL VOLUME 14 NUMBER 1 PAPER 3 APRIL 2011}

Table 6 - Continued

\begin{tabular}{|c|c|}
\hline d & ice \\
\hline & $\begin{array}{l}\text { wei Ge, J., Xiao, J., qiu Fang, Y. \& dan Wang, G., "Incorporating aspects into UML state machine", In Proceedings of the 3rd Internatio } \\
\text { Conference on Advanced Computer Theory and Engineering (ICACTE 2010), volume 2, pp. 505-508, Chengdu, China. }\end{array}$ \\
\hline S27 & $\begin{array}{l}\text { Gowthaman, K., Mustafa, K. \& Khan, R. A., "Reengineering Legacy Source Code to Model Driven Architecture", In Proceedings of the } \\
\text { 4th Annual ACIS International Conference on Computer and Information Science (CCIS 2005), 2005, pp. 262-267, Jeju Isl, South Korea. }\end{array}$ \\
\hline S28 & $\begin{array}{l}\text { Grundy, J. \& Patel, R., "Developing Software Components with the UML, Enterprise Java Beans and Aspects", In Proceedings of the } \\
\text { Australian Conference on Software Engineering (ASWEC 2001), 2001, pp. 127-136, Canberra, Asutralia. }\end{array}$ \\
\hline S29 & $\begin{array}{l}\text { Grønmo, R. \& Møller-Pedersen, B., "Aspect Diagrams for UML Activity Models", In Proceedings of the 3rd International Symposium on } \\
\text { Applications of Graph Transformations with Industrial Relevance (AGTIVE 2007), 2007, pp. 329-344 (LNCS v.5088), Kassel, Germany. }\end{array}$ \\
\hline S30 & $\begin{array}{l}\text { Herrero, J., Sanchez, F. \& Toro, M., "Fault tolerance as an aspect using JReplica", In Proceedings of the 8th Workshop on Future Trends } \\
\text { of Distributed Computing Systems (FTDCS 2001), 2001, pp. 201-207, Bologna, Italy. }\end{array}$ \\
\hline S31 & $\begin{array}{l}\text { Ho, W.-M., Jézéquel, J.-M., Pennaneac’h, F. \& Plouzeau, N., "A to } \\
\text { lst international conference on Aspect-oriented software developm }\end{array}$ \\
\hline S32 & $\begin{array}{l}\text { Hovsepyan, A., Baelen, S., Berbers, Y. \& Joosen, W., "Generic Reusable Concern Compositions", In Proceedings of the 4th European } \\
\text { conference on Model Driven Architecture Fondations and Applications (ECMDA-FA 2008), 2008, pp. 231-245, Berlin, Germany. }\end{array}$ \\
\hline S33 & $\begin{array}{l}\text { Jacobson, I. \& Ng, P-W., Aspect-Oriented Software Development with Use Cases, Addison-Wesley Object Tech } \\
\text { Wesley Professional, 2004. }\end{array}$ \\
\hline S34 & 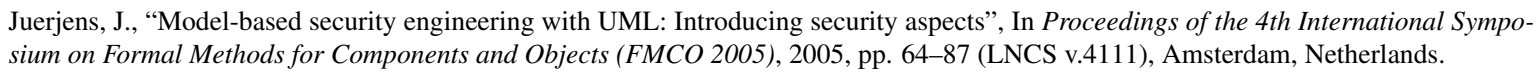 \\
\hline S35 & $\begin{array}{l}\text { Júnior, J. U., Camargo, V. V. \& Chavez, C. V. F., "UML-AOF: a profile for modeling aspect-oriented framewo } \\
\text { modeling workshop (AOM 2009), 8th International Conference on Aspect-Oriented Software Development } \\
\text { Charlottesville, USA. }\end{array}$ \\
\hline S36 & $\begin{array}{l}\text { ior, J. U., Penteado, R. D. \& Camargo, V. V., "An overview and an empirical evaluation of UML-AOF: an UML profile for aspect- } \\
\text { ented frameworks", In Proceedings of the } 2010 \text { ACM Symposium on Applied Computing (SAC 2010), 2010, pp. 2289-2296, Sierre, } \\
\text { itzerland. }\end{array}$ \\
\hline S37 & . \\
\hline S38 & Al Ahed W \& Klein I "Asnect-oriented multi-view modelino" In Proceedinos of the 8th intern \\
\hline S39 & $\begin{array}{l}\text { H., Zhang, J. \& Chen, Y., "Aspect-oriented modeling in software architecture pattern based on UML Computer and Automation } \\
\text { gineering (ICCAE)", In Proceedings of the 2nd International Conference on Computer and Automation Engineering (ICCAE 2010), } \\
\text { ume 3, pp. 575-578, Singapore, Malaysia. }\end{array}$ \\
\hline S40 & I "A mluna \\
\hline S41 & 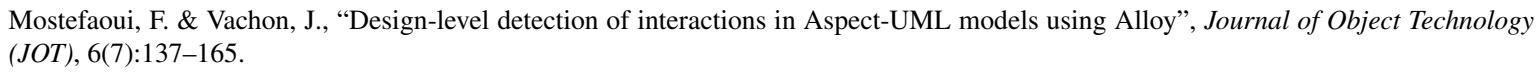 \\
\hline S42 & ., Talhi, C., Lima, V., Debbabi, M., Wang, L. \& Pourzandi \\
\hline S4 & $\begin{array}{l}\text { Muley, K., Suman, U. \& Ingle, M., "Representing join point in UML using pointcuts", In Proceedings of the International Conference or } \\
\text { Computer and Communication Technology (ICCCT 2010), 2010, pp. 557-561, Allahabad, Uttar Pradesh. }\end{array}$ \\
\hline S44 & $\begin{array}{l}\text { Nakajima, S. \& Tamai, T., "Aspect-oriented software d } \\
\text { workshop on Scenarios and state machines: models, algo }\end{array}$ \\
\hline S45 & $\begin{array}{l}\text { Naufal, R. A., Silveira, F. F. \& Guerra, E. M., "A Collaborative Support Approach on UML Sequence Diagrams for Aspect-Oriented } \\
\text { Software", In Workshop Proceedings of the 28th of the International Conference on Conceptual Modeling (ER 2009), 2009, pp. 116-125 } \\
\text { (LNCS v.5833), Gramado, Brazil. }\end{array}$ \\
\hline S46 & $\begin{array}{l}\text { Naveed, M., Abdullah, M. K., Rashid, K. \& Ahmad, H. F., "Representing Shared Join Points with State Charts: A High Level Design } \\
\text { Approach", In World Academy of Science Engineering and Technology (WASET 2006), 2006, volume 15, pp. 80-84, Melbourne, Australia. }\end{array}$ \\
\hline S47 & $\begin{array}{l}\text { Nemuraite, L. \& Balandyte, M., "Aspect-Oriented Use Cases and Crosscutting Interfaces for Reconfigurable Behavior Modeling", In } \\
\text { Proceeding of the 7th International Baltic Conference on Databases and Information Systems (DBIS 2006), 2006, pp. 189-202, Vilnius, } \\
\text { Lithuania. }\end{array}$ \\
\hline S48 & $\begin{array}{l}\text { Netinant, P. \& Pukdesree, S., "Separation of concerns in automation of code generation", In Proceedings of the 5th IASTED Internationa } \\
\text { Conference on Advances in Computer Science and Technology (ACST 2008), 2008, pp. 91-96, Langkawi, Malaysia. }\end{array}$ \\
\hline S49 & $\begin{array}{l}\text { Nouh, M., Ziarati, R., Mouheb, D., Alhadidi, D., Debbabi, M., Wang, L. \& Pourzandi, M., "Aspect weaver: a model transformation } \\
\text { approach for UML models", In Proceedings of the } 2010 \text { Conference of the Center for Advanced Studies on Collaborative Research } \\
\text { (CASCON 2010), 2010, pp. 139-153, Toronto, Canada. }\end{array}$ \\
\hline
\end{tabular}




\section{CLEI ELECTRONIC JOURNAL VOLUME 14 NUMBER 1 PAPER 3 APRIL 2011}

Table 6 - Continued

\begin{tabular}{ll}
\hline Id & Reference \\
\hline S50 & $\begin{array}{l}\text { Petriu, D. C., Shen, H. \& Sabetta, A., "Performance analysis of aspect-oriented UML models". Software and Systems Modeling (SSM), } \\
\text { 6(4):453-471 }\end{array}$ \\
S51 & $\begin{array}{l}\text { Ping, Z. \& Yang, S., "Understanding the aspects from various perspectives in aspects-oriented software reverse engineering", In Proceed- } \\
\text { ings of the International Conference on Computer Application and System Modeling (ICCASM 2010), 2010, volume 11, pp.311-314, } \\
\text { Taiyuan, China. }\end{array}$ \\
S52 & $\begin{array}{l}\text { Przybylek, A., "Separation of crosscutting concerns at the design level: An extension to the UML metamodel", In Proceedings of the } \\
\text { International Multiconference on Computer Science and Information Technology (IMCSIT 2008), 2008, volume 3, pp. 551-557, Wisla, } \\
\text { Poland. }\end{array}$
\end{tabular}

S53 Reddy, Y. R., Ghosh, S., France, R. B., Straw, G., Bieman, J. M., McEachen, N., Song, E. \& Georg, G., "Directives for composing aspect-oriented design class models", In Transactions on Aspect-Oriented Software Development I, pp. 75-105 (LNCS v.3880)

S54 Rui, W., Xiao-Guang, M., Zi-Ying, D. \& Yan-Ni, W., "Extending UML for Aspect-Oriented Architecture Modeling", In Proceedings of the 2nd International Workshop on Computer Science and Engineering (WCSE 2009) 2009, pp. 362-366, Qingdao, China.

S55 Sánchez, P., Stein, D. \& Hanenberg, S., "Statecharts as an intermediate representation of JPDDs which help developers to map them to executable artifacts", In Proceedings of the 12th international workshop on Aspect-oriented modeling (AOM 2008), 2008, pp. 31-36, Brussels, Belgium.

S56 Sharafi, Z., Mirshams, P., Hamou-Lhadj, A. \& Constantinides, C., "Extending the UML Metamodel to Provide Support for Crosscutting Concerns", In Proceedings of the Eighth ACIS International Conference on Software Engineering Research, Management and Applications (SERA 2010), 2010, pp.149-157, Montreal, Canada.

S57 Sharif, H., Rehan, S. \& Farrukh, G. A., "Aspect-oriented requirements engineering: A use case based approach", In Proceedings of the 9th International Multitopic Conference (INMIC 2005), 2005, pp. 566-570, Karachi, Pakistan.

S58 Shen, W. \& Wong, W. E., "Flexible Aspect-Oriented Design Model Checking", In Proceedings of the 15th Asia-Pacific Software Engineering Conference (APSEC 2008), 2008, pp. 537-544, Beijing, China.

S59 Somé, S. \& Anthonysamy, P. "An approach for aspect-oriented use case modeling", In Proceedings of the 13th international Workshop on Early Aspects (WEA 2008), 2008, pp. 27-33, Leipzig, Germany

S60 Stein, D., Hanenberg, S. \& Unland, R., "A UML-based aspect-oriented design notation for AspectJ”, In Proceedings of the 1st international conference on Aspect-oriented software development (AOSD 2002), 2002, pp. 106-112, Enschede, The Netherlands.

S61 Stein, D., Hanenberg, S. \& Unland, R., "Join point designation diagrams: A graphical representation of join point selections", International Journal of Software Engineering and Knowledge Engineering (IJSEKE), 2006, 16(3):317-346.

S62 Su, Y., Li, F., Hu, S.-M. \& Chen, P., "Aspect-oriented software reverse engineering”, Journal of Shanghai University (JSU), 2006, 10(5):402-408.

S63 Su, Y., Zhou, X.-W. \& Zhang, M.-Q., "Research on Modeling Traversing Features in Concurrent Software System”, In Proceedings of the 2008 International Conference on Computer Science and Software Engineering (CSSE 2008), 2008, pp. 81-84, Wuhan, China.

S64 Wang, B., Zhu, C. \& Sheng, J., “A Formal Description Method for Aspect-Oriented Statechart Based on CSP”, In Proceedings of the 2008 International Symposium on Computer Science and Computational Technology (ISCSCT 2008), 2008, volume 2, pp. 750-753, Wuhan, China.

S65 Wang, C.-M., Huang, C.-C., Chen, H.-M. \& Wang, S.-T., "Conformance Checking of Running Programs in Dynamic Aspect-Oriented Systems", In Proceedings of the 14th Asia-Pacific Software Engineering Conference (APSEC 2007), 2007, pp. 183-190, Nagoya, Japan.

S66 Wang, Y., Singh, S., Hosking, J. \& Grundy, J., "An aspect-oriented UML tool for software development with early aspects”, In Proceedings of the 2006 international workshop on Early aspects at ICSE (EA 2006), 2006, pp. 51-58, Shanghai, China.

S67 Wehrmeister, M., Freitas, E., Pereira, C. \& Wagner, F., "An aspect-oriented approach for dealing with non-functional requirements in a model-driven development of distributed embedded real-time systems", In Proceedings of the 10th IEEE International Symposium on Object and Component-Oriented Real-Time Distributed Computing (ISORC 2007), 2007, pp. 428-432, Santorini Island, Greece.

S68 Whittle, J., Jayaraman, P., Elkhodary, A., Moreira, A. \& Araújo, J., "MATA: A unified approach for composing UML aspect models based on graph transformation", In Transactions on Aspect-Oriented Software Development VI, 2009, pp. 191-237 (LNCS v.5560).

S69 Woodside, M., Petriu, D. C., Petriu, D. B., Xu, J., Israr, T., Georg, G., France, R., Bieman, J. M., Houmb, S. H. \& Jürjens, J., "Performance analysis of security aspects by weaving scenarios extracted from UML models", Journal of Systems and Software (JSS), 82(1):56-74.

S70 Xu, D., Xu, W. \& Wong, W. E., "Testing aspect-oriented programs with UML design models", International Journal of Software Engineering and Knowledge Engineering (IJSEKE), 18(3):413-437.

S71 Xu, Y., Tang, S., Xu, Y. \& Tang, Z., “Towards aspect oriented web service composition with UML”, In Proceedings of the 6th IEEE/ACIS International Conference on Computer and Information Science (CCIS 2007), 2007, pp. 279-284, Melbourne, Australia.

S72 Yang, S. \& Jun, Q., "Approach on modeling crosscutting features in concurrent system", In Proceedings of the Sixth International Conference on Networked Computing and Advanced Information Management (NCM 2010), 2010, pp. 133-138, Seoul, Korea.

S73 Zhang, G., "Towards Aspect-Oriented Class Diagrams", In Proceedings of the 12th Asia-Pacific Software Engineering Conference (APSEC 2005), 2005, pp. 763-768, Taipei, Taiwan

Continued... 


\section{CLEI ELECTRONIC JOURNAL VOLUME 14 NUMBER 1 PAPER 3 APRIL 2011}

Table 6 - Continued

\begin{tabular}{|c|c|}
\hline Id & Reference \\
\hline S74 & $\begin{array}{l}\text { Zhang, G., Hoelzl, M. \& Knapp, A., "Enhancing UML state machines with aspects", In Proceedings of the 10th International Conference } \\
\text { on Model Driven Engineering Languages and Systems (MODELS 2007), 2007, pp. 529-543 (LNCS v.4735), Nashville, USA. }\end{array}$ \\
\hline S75 & $\begin{array}{l}\text { Zhang, J., Chen, Y. \& Liu, G., "The Realization of Aspectual State Model with UML Extension Mechanism", In Proceedings of the 4th } \\
\text { IEEE Conference on Industrial Electronics and Applications (ICIEA 2009), 2009, pp. 3059-3063, Xian, China. }\end{array}$ \\
\hline S76 & $\begin{array}{l}\text { Zhang, J., Chen, Y. \& Liu, G., "Modeling Aspect-Oriented Programming with UML Profile", In Proceedings of the 1st International } \\
\text { Workshop on Education Technology and Computer Science (ETCS 2009), 2009, volume 2, pp. 242-245, Wuhan, Hubei. }\end{array}$ \\
\hline S77 & $\begin{array}{l}\text { Zhang, J., Chen, Y., Liu, G. \& Li, H., "Using Sequence Diagram to Support Aspect-Oriented Programming in MDA", In Proceedings of } \\
\text { the 1st International Conference on Intelligent Human-Machine Systems and Cybernetics (IHMSC 2009), 2009, pp. 359-362, Hangzhou, } \\
\text { China. }\end{array}$ \\
\hline S78 & $\begin{array}{l}\text { Zhang, J., Chen, Y., Zhang, Y. \& Li, H., "Aspect-oriented modeling and mapping driven by Model Driven Architecture", In Proceedings } \\
\text { of the 2nd IEEE International Conference on Computer Science and Information Technology (ICCSIT 2009), 2009, pp. 180-184, Beijing, } \\
\text { China. }\end{array}$ \\
\hline S79 & $\begin{array}{l}\text { Zhang, J., Li, F. \& Zhang, Y., “Aspect-Oriented Requirements Modeling”, In Proceedings of the 31st IEEE Software Engineering Workshop } \\
\text { (SEW 2008), 2008, pp. 35-40, Columbia, USA. }\end{array}$ \\
\hline S80 & $\begin{array}{l}\text { Zhang, J., Li, H. \& Li, F., "Research on Aspect Connectors for Software Architecture Adaptation", In Proceedings of the 31st IEEE } \\
\text { Software Engineering Workshop (SEW 2007), 2007, pp. 63-66, Columbia, USA. }\end{array}$ \\
\hline S81 & $\begin{array}{l}\text { Zhang, L. "Aspect-Oriented Analysis for Embedded Real-Time Systems", In Proceedings of the Advanced Software Engineering and Its } \\
\text { Applications (ASEA 2008), 2008, pp. 53-56, Hainan Island, China. }\end{array}$ \\
\hline S82 & $\begin{array}{l}\text { Zhou, X.-c., Liu, C., Niu, Y.-t. \& Lai, T.-z., "Towards a Framework of Aspect-Oriented Modeling with UML", In Proceedings of the } \\
\text { International Symposium on Computer Science and Computational Technology (ISCSCT 2008), 2008, volume 2, pp. 738-741, Shanghai, } \\
\text { China. }\end{array}$ \\
\hline $\mathrm{S} 83$ & $\begin{array}{l}\text { Zhou, Y., Lei, G., Li, P. \& Kong, L., "Realizing extension use cases with AOP", In Proceedings of the International Symposium on IT in } \\
\text { Medicine and Education (ITME 2008), 2008, pp. 1040-1044, Xiamen, China. }\end{array}$ \\
\hline S84 & $\begin{array}{l}\text { Zhu, Z. J. \& Zulkernine, M., "A model-based aspect-oriented framework for building intrusion-aware software systems", Information and } \\
\text { Software Technology (IST), 51(5):865-875. }\end{array}$ \\
\hline
\end{tabular}

\section{Appendix B}

This section presents the meaning of the abbreviations found in the map to the category "Main Events and Journals" (in Figure 6). Table 7 lists the journals and Table 8 lists the events where the primary studies were published.

Table 7: Abbreviations of Journals

\begin{tabular}{ll}
\hline Abbreviation & Journal \\
\hline IJSEKE & International Journal of Software Engineering and Knowledge Engineering \\
IPS & IEE Proceedings-Software \\
IST & Information and Software Technology \\
JOT & Journal of Object Technology \\
JSS & Journal of Systems and Software \\
JSU & Journal of Shanghai University \\
SSM & Software and Systems Modeling \\
\hline
\end{tabular}

Table 8: Abbreviations of Events

\begin{tabular}{ll}
\hline Abbreviation & Event \\
\hline ACST & Advances in Computer Science and Technology \\
AGTIVE & Applications of Graph Transformations with Industrial Relevance \\
AOM & Aspect-oriented modeling \\
AOSD & Aspect-oriented software development \\
APSEC & Asia-Pacific Software Engineering Conference \\
ASEA & Advanced Software Engineering and Its Applications \\
ASWEC & Australian Conference on Software Engineering \\
\hline
\end{tabular}


CLEI ELECTRONIC JOURNAL VOLUME 14 NUMBER 1 PAPER 3 APRIL 2011

Table 8 - Continued

\begin{tabular}{|c|c|}
\hline Abbreviation & Event \\
\hline $\mathrm{C} 3 \mathrm{~S} 2 \mathrm{E}$ & Canadian Conference on Computer Science and Software Engineering \\
\hline CASCON & Center for Advanced Studies on Collaborative Research \\
\hline CCIS & Conference on Computer and Information Science \\
\hline CSIE & Computer Science and Information Engineering \\
\hline CSSE & Computer Science and Software Engineering \\
\hline DBIS & International Baltic Conference on Databases and Information Systems \\
\hline EA & Workshop on Early Aspects \\
\hline ECMDA-FA & European conference on Model Driven Architecture \\
\hline ER & International Conference on Conceptual Modeling \\
\hline ETCS & Education Technology and Computer Science \\
\hline FMCO & Formal Methods for Components and Objects \\
\hline FTDCS & Future Trends of Distributed Computing Systems \\
\hline GPCE & International Conference on Generative Programming and Component Engineering \\
\hline HASE & High-Assurance Systems Engineering \\
\hline HICSS & Hawaii International Conference on System Sciences \\
\hline ICACTE & International Conference on Advanced Computer Theory and Engineering \\
\hline ICCAE & International Conference on Computer and Automation Engineering \\
\hline ICCASM & International Conference on Computer Application and System Modeling \\
\hline ICCCT & International Conference on Computer and Communication Technology \\
\hline ICCSIT & International Conference on Computer Science and Information Technology \\
\hline ICEE & International Conference on E-Business and E-Government \\
\hline ICIEA & IEEE Conference on Industrial Electronics and Applications \\
\hline ICSE & International Conference on Software Engineering \\
\hline ICITTA & International Conference on Information and Communication Technologies: From Theory to Applications \\
\hline IHMSC & Intelligent Human-Machine Systems and Cybernetics \\
\hline IMCSIT & International Multiconference on Computer Science and Information Technology \\
\hline INFOS & International Conference on Informatics and Systems \\
\hline INMIC & International Multitopic Conference \\
\hline ISCC & IEEE Symposium on Computers and Communications \\
\hline ISCSCT & International Symposium on Computer Science and Computational Technology \\
\hline ISORC & International Symposium on Object and Component-Oriented Real-Time Distributed Computing \\
\hline ITME & IT in Medicine and Education \\
\hline MiSE & Models in Software Engineering \\
\hline MODELS & International Conference on Model Driven Engineering Languages and Systems \\
\hline $\mathrm{NCM}$ & Networked Computing and Advanced Information Management \\
\hline SAC & Symposium on Applied Computing \\
\hline SCES & Scenarios and state machines: models, algorithms, and tools \\
\hline SEA & Software Engineering and Applications \\
\hline SEPS & Software Engineering for Pervasive Services \\
\hline SERA & Software Engineering Research, Management and Applications \\
\hline SEW & Software Engineering Workshop \\
\hline WASET & World Academy of Science Engineering and Technology \\
\hline WCSE & Workshop on Computer Science and Engineering \\
\hline WMSCI & World Multi-Conference on Systemics, Cybernetics and Informatics \\
\hline
\end{tabular}




\section{CLEI ELECTRONIC JOURNAL VOLUME 14 NUMBER 1 PAPER 3 APRIL 2011}

\section{Appendix C}

Table 9 presents the complete list of primary studies classified in each category established for the map "UML Diagrams to Represent Aspect-oriented Systems". Table 10 presents the complete list of primary studies classified in each category established for the map "Main Keywords".

Table 9: List of primary studies related to the map "UML Diagrams to Represent Aspect-oriented Systems"

\begin{tabular}{ll}
\hline UML Diagram & Primary Studies \\
\hline Use Case & S5, S33, S47, S48, S51, S57, S59, S60, S62, S67, S83 \\
State Machine & S1, S4, S7, S13, S19, S25, S26, S30, S34, S37, S38, S44, S46, S48, S55, S63, S64, S67, S68, S74, \\
Communication & S75, S79, S81 \\
Sequence & S39, S81 \\
& S4, S7, S8, S10, S11, S16, S32, S37, S38, S39, S40, S42, S43, S45, S48, S51, S55, S56, S60, S61, \\
Activity & S62, S68, S69, S70, S77, S82, S84 \\
Profile & $\mathrm{S} 3, \mathrm{~S} 12, \mathrm{~S} 29, \mathrm{~S} 24, \mathrm{~S} 34, \mathrm{~S} 40, \mathrm{~S} 49, \mathrm{~S} 50, \mathrm{~S} 62, \mathrm{~S} 69, \mathrm{~S} 71, \mathrm{~S} 72, \mathrm{~S} 76$ \\
& $\mathrm{~S} 1, \mathrm{~S} 2, \mathrm{~S} 4, \mathrm{~S} 8, \mathrm{~S} 11, \mathrm{~S} 12, \mathrm{~S} 14, \mathrm{~S} 15, \mathrm{~S} 17, \mathrm{~S} 18, \mathrm{~S} 20, \mathrm{~S} 30, \mathrm{~S} 32, \mathrm{~S} 35, \mathrm{~S} 36, \mathrm{~S} 37, \mathrm{~S} 40, \mathrm{~S} 42, \mathrm{~S} 49, \mathrm{~S} 50$, \\
Package & $\mathrm{S} 51, \mathrm{~S} 56, \mathrm{~S} 58, \mathrm{~S} 65, \mathrm{~S} 67, \mathrm{~S} 71, \mathrm{~S} 78, \mathrm{~S} 82$ \\
Deployment & $\mathrm{S} 10, \mathrm{~S} 34, \mathrm{~S} 37, \mathrm{~S} 39, \mathrm{~S} 73$ \\
Component & $\mathrm{S} 34, \mathrm{~S} 50, \mathrm{~S} 69$ \\
Class & $\mathrm{S} 11, \mathrm{~S} 21, \mathrm{~S} 25, \mathrm{~S} 50, \mathrm{~S} 54, \mathrm{~S} 66, \mathrm{~S} 80$ \\
& $\mathrm{~S} 2, \mathrm{~S} 4, \mathrm{~S} 7, \mathrm{~S} 15, \mathrm{~S} 17, \mathrm{~S} 19, \mathrm{~S} 18, \mathrm{~S} 20, \mathrm{~S} 21, \mathrm{~S} 23, \mathrm{~S} 24, \mathrm{~S} 25, \mathrm{~S} 28, \mathrm{~S} 31, \mathrm{~S} 32, \mathrm{~S} 34, \mathrm{~S} 38, \mathrm{~S} 40, \mathrm{~S} 41, \mathrm{~S} 49$, \\
Object & $\mathrm{S} 52, \mathrm{~S} 53, \mathrm{~S} 56, \mathrm{~S} 61, \mathrm{~S} 65, \mathrm{~S} 67, \mathrm{~S} 68, \mathrm{~S} 70, \mathrm{~S} 71, \mathrm{~S} 73, \mathrm{~S} 75, \mathrm{~S} 79, \mathrm{~S} 81, \mathrm{~S} 82, \mathrm{~S} 84$ \\
\hline
\end{tabular}

Table 10: List of primary studies related to the map "Main Keywords"

\begin{tabular}{ll}
\hline Main Keywords & Primary Studies \\
\hline Aspect Composition & S21, S46, S69 \\
Case Study & S1, S8, S12, S18, S25, S26, S32, S36, S40, S45, S50, S51, S56, S63, S67, S72, S80, S82 \\
Component & S11, S16, S21, S25, S28, S45, S50, S54, S64, S80 \\
Composition Mechanism & S5, S32, S50, S53 \\
Framework & S13, S31, S32, S35, S36, S37, S48, S49, S51, S62, S67, S82, S84 \\
Join Point Model & S2, S43, S44, S46 \\
Model-driven Architecture & S1, S8, S77, S78 \\
Model-driven Development & S11, S24, S32 \\
Requirements & S9, S10, S13, S21 \\
Reverse Engineering & S22, S27, S51, S56, S62 \\
Software Architecture & S13, S17, S23, S27, S35, S39, S54, S80 \\
Tool Support & S5, S8, S12, S13, S17, S24, S28, S38, S51, S53, S56, S58, S66, S68 \\
UML Based & S3, S7, S9, S11, S16, S19, S22, S23, S38, S47, S50, S55, S60, S61, S62, S63, S67, S68, S70, S71, \\
& S75, S77, S80 \\
UML Extension & S5, S6, S8, S10, S12, S13, S15, S17, S21, S26, S27, S28, S29, S30, S31, S32, S33, S44, S45, S46, \\
& S51, S52, S54, S56, S57, S58, S59, S64, S65, S66, S69, S73, S74, S76, S78, S81, S83, S84 \\
UML Profile & S1, S4, S14, S20, S21, S25, S34, S35, S36, S37, S40, S41, S42, S49, S82 \\
UML Standard & S48, S53, S79 \\
\hline
\end{tabular}

